\title{
Fibonacci Cordial Labeling of Some Special Graphs
}

\section{A. H. ROKAD}

School of Engineering, RK.University, Rajkot, 360020, Gujarat, India.

\begin{abstract}
An injective function $\mathrm{g}: \mathrm{V}(\mathrm{G}) \rightarrow\left\{\mathrm{F}_{0}, \mathrm{~F}_{1}, \mathrm{~F}_{2}, \ldots, \mathrm{F}_{\mathrm{n}+1}\right\}$, where $\mathrm{F}_{\mathrm{j}}$ is the $\mathrm{j}^{\text {th }}$ Fibonacci number $(j=0,1, \ldots, n+1)$, is said to be Fibonacci cordial labeling if the induced function $g^{*}: E(G) \rightarrow\{0,1\}$ defined by $g$ * $(x y)=(f(x)+f(y))$ (mod2) satisfies the condition $l e_{g}(1)-e_{g}(0) \mid \leq 1$. A graph having Fibonacci cordial labeling is called Fibonacci cordial graph.

In this paper, i inspect the existence of Fibonacci Cordial Labeling of DS(Pn), DS(DFn), Edge duplication in $\mathrm{K}_{1, n}$, Joint sum of $\mathrm{GI}(\mathrm{n})$, DFn $\oplus \mathrm{K}_{1, \mathrm{n}}$ and ringsum of star graph with cycle with one chord and cycle with two chords respectively.
\end{abstract}

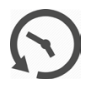

Article History

Received: 09 November 2017

Accepted:17 November 2017

\section{Keywords}

Fibonacci Cordial Labeling,

Degree Splitting,

Edge duplication,

Joint sum,

Ring sum.

\section{Introduction}

The idea of Fibonacci cordial labeling was given by A. H. Rokad and G. V. Ghodasara'. The graphs which i considered here are Simple, undirected, connected and finite. Here $V(G)$ and $E(G)$ denotes the set of vertices and set of edges of a graph $G$ respectively. For different graph theoretic symbols and nomenclature i refer Gross and Yellen ${ }^{3}$. A dynamic survey of labeling of graphs is released and modified every year by Gallian ${ }^{4}$.

\section{Definition 1}

Let $G=(V(G), E(G))$ be a graph with $V=X 1 \cup X 2$ $U X 3 \cup \ldots X_{i} \cup Y$ where each $X_{i}$ is a set of vertices having at least two vertices of the same degree and $Y=V \backslash U X_{i}$. The degree splitting graph of $G$ designated by $D S(G)$ is acquired from $G$ by adding vertices $z_{1}, z_{2}, z_{3}, \ldots, z_{y}$ and joining to each vertex of $x_{i}$ for $i \varepsilon[1, t]$.

\section{Definition 2}

The double fan $\mathrm{DF}_{\mathrm{n}}$ comprises of two fan graph that have a common path. In other words $\mathrm{DF}_{\mathrm{n}}=$ $\mathrm{Pn}+\mathrm{K}_{2}$ ).

\section{Definition 3}

The duplication of an edge $e=x y$ of graph $G$ produces a new graph G' by adding an edge

\footnotetext{
CONTACT Amit H. Rokad amit.rokad@ rku.ac.in 9 School of Engineering, RK.University, Rajkot, 360020, Gujarat, India. (c) 2017 The Author(s). Published by Techno Research Publishers

This is an 6 Open Access article licensed under a Creative Commons Attribution-NonCommercial-ShareAlike 4.0 International License (https://creativecommons.org/licenses/by-nc-sa/4.0/), which permits unrestricted NonCommercial use, distribution, and reproduction in any medium, provided the original work is properly cited.

To link to this article: http://dx.doi.org/10.13005/ojcst/10.04.18
} 
$e^{\prime}=x^{\prime} y^{\prime}$ such that $N\left(x^{\prime}\right)=N(x) \cup\left\{y^{\prime}\right\}-\{y\}$ and $N\left(y^{\prime}\right)$ $=N(y) \cup\left\{x^{\prime}\right\}-\{x\}$.

\section{Definition 4}

The graph obtained by connecting a vertex of first copy of a graph $\mathrm{G}$ with a vertex of second copy of a graph $\mathrm{G}$ is called joint sum of two copies of $\mathrm{G}$.

\section{Definition 5}

A globe is a graph obtained from two isolated vertex are joined by $\mathrm{n}$ paths of length two. It is denoted by $\mathrm{Gl}_{(\mathrm{n})}$.

\section{Definition 6}

Ring sum $G_{1} \oplus G_{2}$ of two graphs $G_{1}=\left(V_{1}\right.$, $\left.E_{1}\right)$ and $G_{2}=\left(V_{2}, E_{2}\right)$ is the graph $G_{1} \oplus G_{2}=$ $\left(V_{1} \cup V_{2},\left(E_{1} \cup E_{2}\right)-\left(E_{1} \cap E_{2}\right)\right)$.

\section{Results}

Theorem 1: DS(Pn) is Fibonacci cordial.

Proof 1

Consider $\mathrm{P}_{\mathrm{n}}$ with $\mathrm{V}\left(\mathrm{P}_{\mathrm{n}}\right)=\{\mathrm{vi}: \mathrm{i} \varepsilon[1, \mathrm{n}]\}$. Here $\mathrm{V}$ $(P n)=X_{1} \cup X_{2}$, where $X_{1}=\left\{X_{i}: 2 \varepsilon[2, n-1]\right\}$ and $X_{2}=\left\{x_{1}, X_{n}\right\}$. To get $D S(P n)$ from $G$ we add $w_{1}$ and $\mathrm{w}_{2}$ corresponding to $X_{1}$ and $X_{2}$. Then $|V(D S(P n))|$ $=\mathrm{n}+2$ and $\mathrm{E}(\mathrm{DS}(\mathrm{Pn}))=\left\{\mathrm{X}_{0} \mathrm{w}_{2}, \mathrm{X}_{2} \mathrm{w}_{2}\right\} \cup\left\{\mathrm{w}_{1} \mathrm{X}_{\mathrm{i}}: \mathrm{i} \varepsilon\right.$ $[2, n-1]\}$. So, $|E(D S(P n))|=-1+2 n$.

I determine labeling function $\mathrm{g}: \mathrm{V}(\mathrm{G}) \rightarrow\left\{\mathrm{F}_{0}, \mathrm{~F}_{1}, \mathrm{~F}_{2}\right.$, $\ldots, \mathrm{F}_{\mathrm{n}+2}$ \} as below:

$\mathrm{g}\left(\mathrm{w}_{1}\right)=\mathrm{F}_{1}$,

$g\left(w_{2}\right)=F_{n+1}$

$\mathrm{g}\left(\mathrm{x}_{1}\right)=\mathrm{F}_{0}$

$g\left(x_{i}\right)=F_{i}, 2 \leq i \leq n$.

Therefore, $\left|e_{g}(1)-e_{g}(0)\right| \leq 1$.

Therefore, $\mathrm{DS}(\mathrm{Pn})$ is a Fibonacci cordial graph.

Example 1: Fibonacci cordial labeling of $\mathrm{DS}\left(\mathrm{P}_{7}\right)$ can be seen in Figure 1.

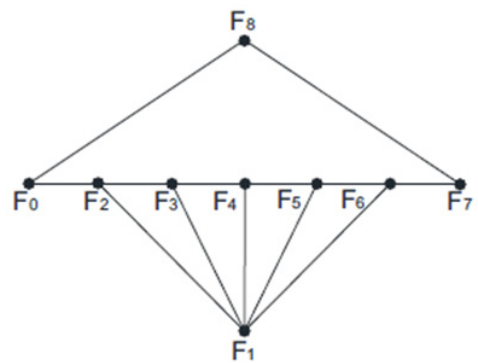

Fig.1
Theorem 2. DS(DFn) is a Fibonacci cordial graph.

Proof 2

Let $\mathrm{G}=\mathrm{Df} \mathrm{f}_{\mathrm{n}}$ be the double fan. Let $\mathrm{x}_{1}, \mathrm{x}_{2}, \ldots, \mathrm{x}_{\mathrm{n}}$ be the path vertices of Dfn and $x$ and $y$ be two apex vertices. To get $\mathrm{DS}\left(\mathrm{Df}_{\mathrm{n}}\right)$ from $\mathrm{G}$, we add $\mathrm{w}_{1}, \mathrm{w}_{2}$ corresponding to $X_{1}, X_{2}$, where $X_{1}=\left\{x_{i}: i \varepsilon[1, n]\right\}$ and $X_{2}=\{x, y\}$. Then $\left|V\left(D S\left(D f_{n}\right)\right)\right|=4+n \& E\left(D S\left(D f_{n}\right)\right)=\left\{x w_{2}, y w_{2}\right\}$ $U\left\{x_{i} w_{1}: i \varepsilon[1, n]\right\}$. So, $\left|E\left(D S\left(D f_{n}\right)\right)\right|=1+4 n$.

I determine labeling function $\mathrm{g}: \mathrm{V}(\mathrm{G}) \rightarrow\left\{\mathrm{F}_{0}, \mathrm{~F}_{1}, \mathrm{~F}_{2}\right.$, $\left.\ldots, \mathrm{F}_{\mathrm{n}+4}\right\}$, as below.

For all $1 \leq \mathrm{i} \leq \mathrm{n}$.

$g\left(w_{1}\right)=F_{3}$,

$g\left(w_{2}\right)=F_{2}$.

$\mathrm{g}(\mathrm{x})=\mathrm{F}_{0}$,

$g(y)=F_{1}$,

$\mathrm{g}\left(\mathrm{x}_{\mathrm{i}}\right)=\mathrm{F}_{\mathrm{i}+3}$

Therefore $\left|e_{g}(1)-e_{g}(0)\right| \leq 1$.

Therefore, DS(DFn) is Fibonacci cordial.

Example 2. Fibonacci cordial labeling of $\mathrm{DS}\left(\mathrm{DF}_{5}\right)$ can be seen in Figure 2.

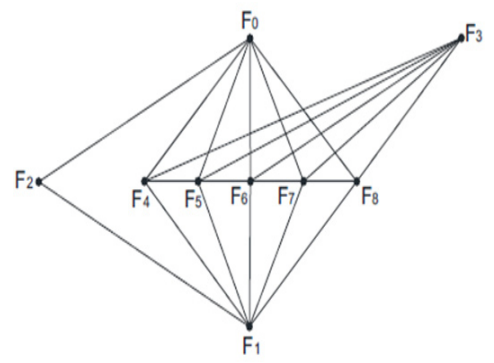

Fig. 2

Theorem 3.The graph obtained by duplication of an edge in $\mathrm{K}_{1, \mathrm{n}}$ is a Fibonacci cordial graph.

\section{Proof 3}

Let $x_{0}$ be the apex vertex and $x_{1}, x_{2}, \ldots, x_{n}$ be the consecutive pendant vertices of $\mathrm{K}_{1, \mathrm{n}}$. Let $\mathrm{G}$ be the graph obtained by duplication of the edge $e=x_{0} x_{n}$ by a new edge $e^{\prime}=x_{0}^{\prime} x_{n}^{\prime}$. Therefore in $G, \operatorname{deg}\left(x_{0}\right)=$ $n, \operatorname{deg}\left(x_{0}^{\prime}\right)=n, \operatorname{deg}\left(v_{n}\right)=1, \operatorname{deg}\left(x_{n}^{\prime}\right)=1$ and $\operatorname{deg}\left(x_{i}\right)$ $=2, \forall \mathrm{i} \varepsilon\{1,2, \ldots \mathrm{n}\}$. Then $\left|\mathrm{V}\left(\mathrm{K}_{1, \mathrm{n}}\right)\right|=\mathrm{n}+3$ and $\mathrm{E}\left(\mathrm{K}_{1, \mathrm{n}}\right)=2 \mathrm{n}$.

I determine labeling function $\mathrm{g}: \mathrm{V}(\mathrm{G}) \rightarrow\left\{\mathrm{F}_{0}, \mathrm{~F}_{1}, \mathrm{~F}_{2}\right.$, . $\ldots, \mathrm{F}_{\mathrm{n}+3}$, as below.

$g\left(x_{0}\right)=F_{1}$,

$g\left(x_{1}\right)=F_{2}$,

$g\left(x_{n-1}\right)=F_{3}$, 
$g\left(x_{0}^{\prime}\right)=F_{0}$,

$g\left(x_{n}^{\prime}\right)=F_{4}$,

$g\left(x_{i}\right)=F_{i+3,}, i \varepsilon[2, n], \quad i \neq n-1$.

Therefore $\left|e_{g}(1)-e_{g}(0)\right| \leq 1$.

Therefore, the graph obtained by duplication of an edge in $\mathrm{K}_{1, \mathrm{n}}$ is a Fibonacci cordial graph.

Example 3. A Fibonacci cordial labeling of the graph obtained by duplication of an edge $\mathrm{e}$ in $\mathrm{K}_{1,8}$ can be seen in the Figure 3.

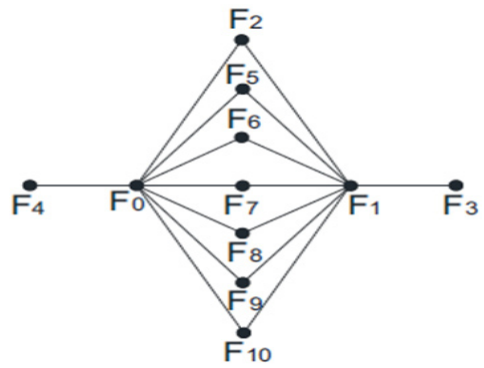

Fig. 3

Theorem 4. The graph obtained by joint sum of two copies of Globe $\mathrm{Gl}_{(\mathrm{n})}$ is Fibonacci cordial. Proof 4

Let $\mathrm{G}$ be the joint sum of two copies of $\mathrm{Gl}_{(\mathrm{n})}$. Let $\left\{x, x^{\prime}, x_{1}, x_{2}, \ldots, x_{n}\right\}$ and $\left\{y, y ', y_{1}, y_{2}, \ldots, y_{n}\right\}$ be the vertices of first and second copy of $\mathrm{Gl}_{(\mathrm{n})}$ respectively.

I determine labeling function $\mathrm{g}: \mathrm{V}(\mathrm{G}) \rightarrow\left\{\mathrm{F}_{0}, \mathrm{~F}_{1}, \mathrm{~F}_{2}\right.$, . $\left.\ldots, \mathrm{F}_{2 n+4}\right\}$, as below.

$\mathrm{g}(\mathrm{x})=\mathrm{F}_{0}$,

$g\left(x^{\prime}\right)=F_{1}$,

$g(x i)=F_{i+3}, i \varepsilon[1, n]$.

$g(y)=F_{2}$,

$g\left(y^{\prime}\right)=F_{3}$,

$g(y i)=F_{n+i+3}$, i $\varepsilon[1, n]$.

From the above labeling pattern i have $e_{g}(0)=n+$ 1 and $e_{g}(1)=n$.

Therefore $\left|e_{g}(1)-e_{g}(0)\right| \leq 1$.

Thus, the graph obtained by joint sum of two copies of Globe $\mathrm{Gl}_{(\mathrm{n})}$ is Fibonacci cordial.

Example 4. Fibonacci cordial labeling of the joint sum of two copies of Globe $\mathrm{Gl}_{(7)}$ can be seen in Figure 4.

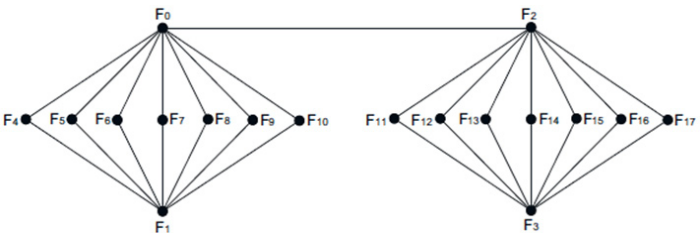

Fig. 4

Theorem 5. The graph $D F_{n} \oplus K_{1, n}$ is a Fibonacci cordial graph for every $\mathbf{n} \boldsymbol{\varepsilon} \mathbf{N}$.

Proof 5

Assume $\mathrm{V}\left(\mathrm{DF}_{\mathrm{n}} \oplus \mathrm{K}_{1, \mathrm{n}}\right)=\mathrm{X}_{1} \cup \mathrm{X}_{2}$, where $\mathrm{X}_{1}=$ $\left\{x, w, x_{1}, x_{2}, \ldots, x_{n}\right\}$ be the vertex set of DFn and $X_{2}$ $=\left\{\mathrm{y}=\mathrm{w}, \mathrm{y}_{1}, \mathrm{y}_{2}, \ldots, \mathrm{y}_{\mathrm{n}}\right\}$ i s the vertex set of $\mathrm{K}_{1, \mathrm{n}}$. Here $v$ is the apex vertex \& $y_{1}, y_{2}, \ldots, y_{n}$ are pendant vertices of $K_{1, n}$.

Also IV $\left(\mathrm{DF}_{\mathrm{n}} \oplus \mathrm{K}_{1, \mathrm{n}}\right)|=2 \mathrm{n}+2,| \mathrm{E}\left(\mathrm{DF}_{\mathrm{n}} \oplus \mathrm{K}_{1, \mathrm{n}}\right) \mid=$ $4 n-1$.

I determine labeling function $\mathrm{g}: \mathrm{V}\left(\mathrm{DF}_{\mathrm{n}} \oplus \mathrm{K}_{1, \mathrm{n}}\right) \rightarrow\left\{\mathrm{F}_{0}\right.$, $\left.F_{1}, F_{2}, \ldots, F_{2 n+2}\right\}$, as below.

For all $1 \leq \mathrm{i} \leq \mathrm{n}$.

$\mathrm{g}(\mathrm{x})=\mathrm{F}_{0}$,

$g(w)=F_{1}$,

$g\left(x_{i}\right)=F_{i+1}$,

$g\left(y_{i}\right)=F_{n+i+1}$,

From the above labeling pattern i have $e_{g}(0)=2 n$ and $e_{g}(1)=2 n-1$.

Therefore ||$e_{g}(1)-e_{g}(0) \mid \leq 1$.

Thus, the graph $\mathrm{DF}_{\mathrm{n}} \oplus \mathrm{K}_{1, \mathrm{n}}$ is a Fibonacci cordial graph for every $n \varepsilon \mathrm{N}$.

Example 5. Fibonacci cordial labeling of $\mathrm{DF}_{5} \oplus \mathrm{K}_{1,5}$ can be seen in Figure 5.

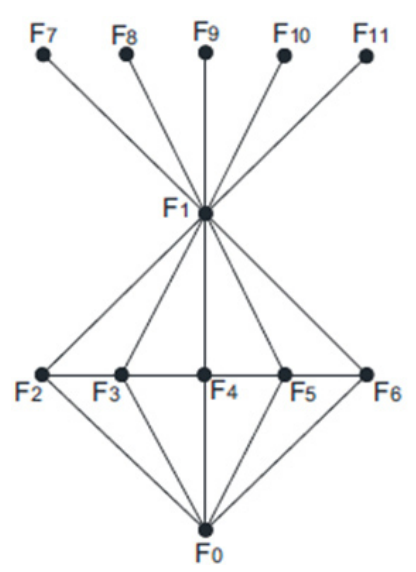

Fig. 5 
Theorem 6. The graph $\mathbf{G} \oplus \mathrm{K}_{1, \mathrm{n}}$ is a Fibonacci cordial graph for all $n \geq 4, n \in N$, where $G$ is the cycle $C_{n}$ with one chord forming a triangle with two edges of $C_{n}$.

\section{Proof 6}

Let $\mathrm{G}$ be the cycle $\mathrm{C}_{\mathrm{n}}$ with one chord. Let $\mathrm{V}(\mathrm{G} \oplus$ $\left.K_{1, n}\right)=X_{1} \cup X_{2}$, where $X_{1}$ is the vertex set of $G$ \& $X_{2}$ is the vertex set of $K_{1, n}$. Let $x_{1}, x_{2}, \ldots, x_{n}$ be the successive vertices of $C n$ and $e=x_{2} x_{n}$ be the chord of $C_{n}$. The vertices $x_{1}, x_{2}, x_{n}$ form a triangle with the chord e. Here $v$ is the apex vertex \& $y_{1}, y_{2}, \ldots, y_{n}$ are pendant vertices of $\mathrm{K}_{1, \mathrm{n}}$.

Take $y=x_{1}$. Also IV $\left(G \oplus K_{1, n}\right)|=2 n| E,\left(G \oplus K_{1, n}\right) \mid$ $=2 n+1$.

I determine labeling function $\mathrm{g}: \mathrm{V}\left(\mathrm{G} \oplus \mathrm{K}_{1, \mathrm{n}}\right) \rightarrow\left\{\mathrm{F}_{0}\right.$, $\left.F_{1}, F_{2}, \ldots, F_{2 n}\right\}$, as below.

Case I: $\mathbf{n} \equiv \mathbf{0}(\bmod 3)$.

For all $1 \leq \mathrm{i} \leq \mathrm{n}$.

$g\left(x_{i}\right)=F_{i}$.

$g\left(y_{i}\right)=F_{n+i}$.

Case II: $n \equiv \mathbf{1}(\bmod 3)$.

$g\left(x_{i}\right)=F_{i}, 1 \leq i \leq n$.

$g\left(y_{1}\right)=F_{0}$,

$\mathrm{g}\left(\mathrm{y}_{\mathrm{i}}\right)=\mathrm{F}_{\mathrm{n+i-1}-1}, 2 \leq \mathrm{i} \leq \mathrm{n}$.

From the above labeling pattern $i$ have $e_{g}(0)=n$ and $e_{g}(1)=n+1$.

Therefore $\left|e_{g}(1)-e_{g}(0)\right| \leq 1$.

Thus, the graph $\mathrm{G} \oplus \mathrm{K}_{1, \mathrm{n}}$ is a Fibonacci cordial graph.

Example 6. A Fibonacci cordial labeling of ring sum of $\mathrm{C}_{7}$ with one chord and $\mathrm{K}_{1,7}$ can be seen in Figure 6.

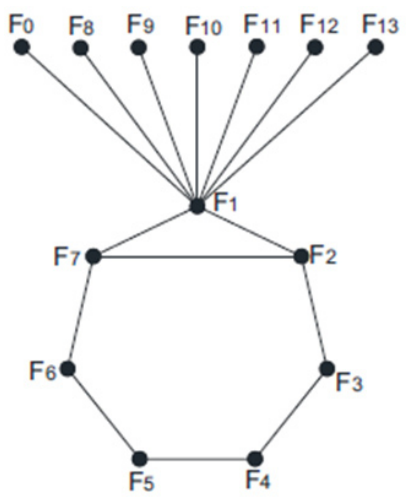

Fig. 6
Theorem 7. The graph $\mathbf{G} \oplus \mathbf{K}_{1, \mathrm{n}}$ is a Fibonacci cordial graph for all $n \geq 5, n \varepsilon N$, where $G$ is the cycle with twin chords forming two triangles and another cycle $C_{n-2}$ with the edges of $C_{n}$. Proof 7

Let $\mathrm{G}$ be the cycle $\mathrm{C}_{\mathrm{n}}$ with twin chords, where chords form two triangles and one cycle $C_{n-2}$. Let $V(G \oplus$ $\left.\mathrm{K}_{1, \mathrm{n}}\right)=\mathrm{X}_{1} \cup \mathrm{X}_{2} . \mathrm{X}_{1}=\left\{\mathrm{X}_{1}, \mathrm{X}_{2}, \ldots, \mathrm{X}_{\mathrm{n}}\right\}$ is the vertex set of $C_{n}, e_{1}=x_{n} x_{2}$ and $e_{2}=x_{n} x_{3}$ are the chords of $C_{n} . X_{2}=\left\{y=x_{1}, y_{1}, y_{2}, \ldots, y_{n}\right\}$ is the vertex set of $\mathrm{K}_{1, \mathrm{n}}$, where $\mathrm{y}_{1}, \mathrm{y}_{2}, \ldots, \mathrm{y}_{\mathrm{n}}$ are pendant vertices and $\mathrm{y}$ $=x_{1}$ is the apex vertex of $K_{1, n}$. Also $\left|V\left(G \oplus K_{1, n}\right)\right|=$ $2 n,\left|E\left(G \oplus K_{1, n}\right)\right|=2 n+2$.

I determine labeling function $\mathrm{g}: \mathrm{V}\left(\mathrm{G} \oplus \mathrm{K}_{1, \mathrm{n}}\right) \rightarrow\left\{\mathrm{F}_{0}\right.$, $\mathrm{F}_{1}, \mathrm{~F}_{2}, \ldots, \mathrm{F}_{2 \mathrm{n}}$, as below.

$g\left(x_{1}\right)=F_{1}$

$g\left(x_{2}\right)=F_{2}$,

$\mathrm{g}\left(\mathrm{x}_{3}\right)=\mathrm{F}_{3}$,

$g\left(x_{n}\right)=F_{4}$,

$g\left(x_{i}\right)=F_{i+1}, 4 \leq i \leq n-1$.

$\mathrm{g}\left(\mathrm{y}_{\mathrm{i}}\right)=\mathrm{F}_{\mathrm{n+i}}, 1 \leq \mathrm{i} \leq \mathrm{n}$.

From the above labeling pattern i have $e_{g}(0)=e_{g}$ (1) $=n+1$.

Therefore $\left|e_{g}(1)-e_{g}(0)\right| \leq 1$.

Thus, The graph $\mathrm{G} \oplus \mathrm{K}_{1, \mathrm{n}}$ is a Fibonacci cordial graph.

Example 7. A Fibonacci cordial labeling of ring sum of $\mathrm{C}_{9}$ with twin chords and $\mathrm{K}_{1,9}$ can be seen in Figure 7.

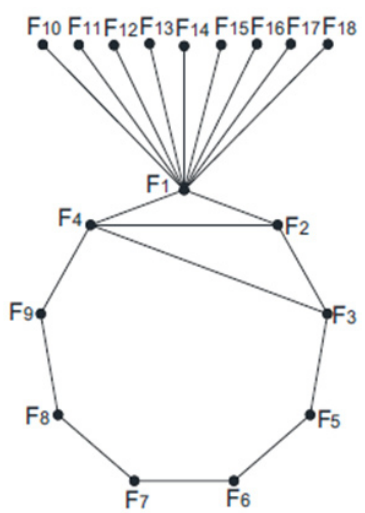

Fig.7

\section{Conclusion}

In this paper i investigate seven new graph which admits Fibonacci cordial labeling. 


\section{References}

1 A. H. Rokad and G. V. Ghodasara, Fibonacci Cordial Labeling of Some Special Graphs, Annals of Pure and Applied Mathematics, Vol. 11, No. 1, 2016, 133 - 144. F. Harary, Graph theory, Addision-wesley, Reading, MA (1969).

3 J Gross and J Yellen, Handbook of graph theory, CRC press (2004).

4 J. A. Gallian, A dynamic survey of graph labeling, The Electronics Journal of Combinatorics, 19 (2012), DS6 1 - 260.

5 M.Sundaram, R. Ponraj, and S. Somasundram, Prime cordial labeling of graphs, Journal of Indian Acadamy of Mathematics, 27 (2005), 373-390.

6 M. A. Seoud and M. A. Salim, Two upper bounds of prime cordial graphs, Journal of
Combinatorial Mathematics and Combinatorial Computing, 75 (2010), 95-103.

7 S. K. Vaidya and P. L. Vihol, Prime cordial labeling for some cycle related graphs, International Journal of Open Problems in Computure Science Mathematics, 3, No.5 (2010), 223-232.

8 S. K. Vaidya and P. L. Vihol, Prime cordial labeling for some graphs, Modern Applied Science, 4, No.8 (2010), 119-126.

9 S. K. Vaidya and N. H. Shah, Prime cordial labeling of some graphs, Open Journal of Discrete Mathematics, 2, No. 1 (2012), 11-16. doi:10.4236/ojdm.2012.21003.

10 S. K. Vaidyaa and N. H. Shah, Prime cordial labeling of some wheel related graphs, Malaya Journal of Matematik, 4(1)(2013) 148156. 